\title{
Prevalence of otitis media with effusion among school going children in Bangladesh
}

\author{
Mani Lal Aich', Akhil Chandra Biswas², Miraj Ahmed³, Md Abul Hasnat Joarder ${ }^{4}$, Pran Gopal \\ Datta $^{5}$, M Alauddin 6
}

\begin{abstract}
:
A Prospective study was carried out from Jan 2000 Jan 2003, to find out the prevalence of OME among School children The study was done in Dhaka City and adjacent areas of Dhaka City in Savar, Munshigonj and Keranigonj, Altogether 280 Students aged 4-9 years were interviewed and examined. Nineteen percent children were found to have OME. In the urban community it was $17 \%$, but in rural areas it was $21 \%$. In our study children with OME were more in poorer people, smoker parents and bottle fed babies.
\end{abstract}

Key words: Otitis media with effusion (OME), school children.

\section{Introduction:}

OME is a very common disease in children and since it is largely silent, it is often unnoticed. The presence of fluid in the middle ear attenuates sound transmission which result in a hearing loss. Symptoms of acute infection are not present in $\mathrm{OME}^{1}$.

The presence of OME in Bangladesh has been studied in a limited fashion. In Bangladesh, population is with mixed ethnic background. Weather is moderately variable. Prevalence of $O M E$ is supposed to be variable in rural and urban area of Bangladesh with different socioeconomic background.

\section{Aims and Objectives:}

1. To determine the prevalence of OME among Children in Bangladesh.

1. Assistant Professor \& Resident Surgeon (ENT), Dept. of Otolaryngology and Head-Neck Surgery, Dhaka Medical College, Dhaka.

2. Assistant Professor, Dept. of Otolaryngology and Head-Neck Surgery, Bangladesh Medical College, Dhanmondi, Dhaka.

3. Medical Officer, Dept. of Otolaryngology-Head \& Neck Surgery, Dhaka Medical College, Dhaka.

4. Professor, Department of Otolaryngology-Head \& Neck Surgery, BSMMU, Dhaka.

5. Professor, Department of Otolaryngology-Head \& Neck Surgery, BSMMU, Dhaka.

6. Professor of Otolaryngology-Head \& Neck Surgery. Address of Correspondence: Dr. Mani Lal Aich, Assistant Professor, \& Resident Surgeon (ENT) Dept. of Otolaryngology and Head-Neck Surgery, Dhaka Medical College, Dhaka.
2. To compare the prevalence in rural and urban community in Bangladesh.

3. To evaluate hearing loss in OME.

4. To Evaluate risk factors for development of OME.

Methods:

This was a descriptive type of cross sectional prospective study carried out among the children of the selected schools. Study was carried out in Dhaka City and the adjacent area of Dhaka city in Savar, Munshigonj, and Keranigonj district. The total number of schools we have studied was six; 3 from Dhaka City and 3 from the rural area. Study was conducted for the period of one year from January 2002 to January 2003.

Children of 4 to 9 years of age were included in the study all of which were school going. Children with CSOM and wax in the wear excluded from the study.

Total 280 students were interviewed and examined for the study. We have carried out this study by collecting information through questionnaire survey, Clinical exam and tympanometry. Clinical exam and Otoscopy was done first, then findings were judged and supported by tympanometry A Type B tympanogram is $93 \%$ sensitive in detecting OME with $76 \%$ specificity which is associated with a $25 \mathrm{~dB}$ hearing loss and its negative predictive value is $98 \%$.

All data were analysed by using SPSS.

Results:

Total 280 children from 6 schools were observed and examined; 3 schools from urban and 3 from rural area. 
Out of 280, one hundred and sixty from urban and 120 children from rural schools.

Table-I

Distribution of children by sex.

\begin{tabular}{lccc}
\hline & Frequency & Percent & Cumulative percent \\
\hline Male & 156 & 55.7 & 55.7 \\
Female & 124 & 44.3 & 100.0 \\
\hline Total & 280 & 100.0 & \\
\hline
\end{tabular}

$55.7 \%$ of the children were male and $44.3 \%$ were female. (Table-I).

Table-II Prevalence of OME

\begin{tabular}{lccc}
\hline & Frequency & Percent & $\begin{array}{c}\text { Cumulative } \\
\text { percent }\end{array}$ \\
\hline 4 to 5 years & 65 & 23.2 & 23.2 \\
5.1 to 6 years & 71 & 25.4 & 48.6 \\
6.1 to 7 years & 60 & 21.4 & 70.0 \\
7.1 to 8 years & 48 & 17.1 & 87.1 \\
8.1 to 9 years & 36 & 12.9 & 100.0 \\
\hline Total & 280 & 100.0 & \\
\hline
\end{tabular}

The prevalence which we have obtained in our study among the school going children aged between 4 to 9 years of age is $19 \%$. In the urban community, it is $17 \%$, but in rural areas it is $21 \%$. (Table-II)

The most of our study population is between 5.1- 6 years age. (25.4\%) Then $23.2 \%$ in between $4-5$ years. Others are $21.4 \%$ (6.1-7 years), $17.1 \%$ (7.1-8 years) and $12.9 \%$ (8.1- 9 years)

Highest percentage of mothers (84.6\%) of the children were housewives, $9.3 \%$ were day laborers, $5.4 \%$ had different type of service, $0.7 \%$ were farmers. (Table-III).

Educational level of mothers of the children should 108 (38.6\%) passed secondary exam. Other 78 (27.9\%) Primary, 50 (17.9\%) illiterate, 27 (9.6\%) higher secondary. Degree + honors and Masters 10 (3.6\%) we find out the highest percentage (32\%) in children of illiterate mothers.

\section{Table-III}

Distribution of the respondents by monthly income of family.

\begin{tabular}{lccc}
\hline Taka & Frequency & Percent & $\begin{array}{c}\text { Cumulative } \\
\text { percent }\end{array}$ \\
\hline Upto 2000 & 30 & 10.7 & 10.7 \\
2001 to 4000 & 41 & 14.6 & 25.4 \\
4001 to 6000 & 55 & 19.6 & 45.0 \\
6001 to 8000 & 65 & 23.2 & 68.2 \\
8001 to 10000 & 50 & 17.9 & 86.1 \\
10001 and above & 39 & 13.9 & 100.0 \\
\hline Total & 280 & 100.0 & - \\
\hline
\end{tabular}

The maximum number of family 121 (43.2\%) had 4 children. 97 (34.2\%) had 5 children 32 (11.4\%) had 3 children, 25 (8.9\%) had 6 children and only 5 (1.8\%) have 7 children. We have obtained increased prevalence rate among the large family (37\%).

Table-IV

Distribution of the children by housing

\begin{tabular}{lccc}
\hline & Frequency & Percent & Cumulative percent \\
\hline Zhupri & 18 & 6.4 & 6.4 \\
Kuncha & 77 & 27.5 & 33.9 \\
Semi paka & 32 & 11.4 & 45.4 \\
Paka & 145 & 51.8 & 97.1 \\
Others & 8 & 2.9 & 100.0 \\
\hline Total & 280 & 100.0 & - \\
\hline
\end{tabular}

The study shows 145 (51.8\%) Children lived in paka house; $77(27.5 \%)$ in kuncha, 32 (Il.4\%) semi paka, 18 (6.4\%) live in Zhupri, 8 (2.9) in different type of accommodation. (Table-IV).

The rate of OME was highest among dwellers of Zhupri, kuncha and semi paka houses (33\%).

Table-V

Distribution of parents by smoking habits

\begin{tabular}{lccc}
\hline & Frequency & Percent & Cumulative percent \\
\hline Present & 133 & 47.5 & 47.5 \\
Absent & 147 & 52.5 & 100.0 \\
\hline Total & 280 & 100.0 & \\
\hline
\end{tabular}


Our study points to that 133 parents were smoker and 147 (52.5\%) were nonsmoker. Among the smoker parents $42 \%$ of children had OME. (Table-V).

Table-VI

Distribution of the children by feeding habit

\begin{tabular}{lccc}
\hline & Frequency & Percent & $\begin{array}{c}\text { Cumulative } \\
\text { percent }\end{array}$ \\
\hline Brest feeding & 244 & 87.1 & 87.1 \\
Bottle feeding & 36 & 12.9 & 100.0 \\
\hline Total & 280 & 100.0 & \\
\hline
\end{tabular}

In our study, out of 280 samples 244 (87.1\%) had the habit of breast feeding and $36(12.9 \%)$ had the bottle feeding during their infancy. (Table-VI). Majority of the bottle-fed children had OME. We obtained no history of allergy in $262(93.6 \%)$ and only $18(6.4 \%)$ had history of allergy.

\section{Discussions:}

Many studies of otitis media with effusion have already been undertaken in different countries of the world, especially in European countries and some developing Asian countries. Various risk factors have been identified. These studies have also recommended some measures for prevention and diagnosis for this major health problem worldwide especially mostly in children aged between 2 to 10 years of age. So far in Bangladesh no study has been carried out yet. The disease is a major health problem in school going children in Bangladesh and it affects the children most and people of all socioeconomic status. But it is significantly higher in lower socioeconomic group. This finding is also common with other study. ${ }^{1}$

Prevalence of the present series is similar with the findings of some other Asian and European countries of the world.

The study shows decreasing rate of prevalence with advancing age. There was similar findings in Williamson et al. ${ }^{2} 1994$ study in UK. No statistically significant difference between male and female children or between rural and urban children in Minza BM et al 1996 study in Tanzania and kim CS et al ${ }^{3,4}$.

Some countries have very low prevalence rate of OME while some have abnormally high prevalence of OME in comparison to our study.
We have of obtained prevalence more in rural population than urban area. But the difference is not statistically significant. This finding is also similar with Saim et $\mathrm{al}^{5}$. Some other studies also revealed same findings. Regarding sex we found no difference.

We found OME in children of illiterate mothers in highest percentage. We obtained increased prevalence in large family. Rasmussen ${ }^{6}$ has got relation between OME and family size. Housing standard also affect the prevalence of OME. Probably this is because of bad hygiene and poor sanitation. This leads to more RTI and thereby OME. We have found clear relation between OME and parental smoking. ${ }^{6,7,8,9,10}$. We have found more prevalence of OME in bottle fed babies and less is breast-fed babies.

No relation has been found in relation to the climate of the residence, parental occupation or educational status and family income. Also we have found statistically significant difference between the prevalence rate in rural and urban area. This observation is also similar with some other studies ${ }^{10,11,12}$.

The study was conducted in purposively selected six schools, 3 from Dhaka city and 3 from rural area. Samples are not representing the whole Dhaka city or the whole country. So findings can not be generalized for the whole Bangladesh or Dhaka city.

The age in which OME is more prevalent in whole population can not be detected as the study was done in children only aged between 4-9 year age. The amount of hearing lost of the cases could not be assessed as we failed to use free field audiometer excepting using tuning fork test and cost was other two constraints of this study.

It can be concluded from this study that OME is still a prevalent disease in a developing country like Bangladesh. It can also be concluded that it is prevalent amongst poor populations like slum dwellers, villagers and especially illiterate people, children of smoker parents, from poor housing standard, polluted bathing source and large family size. OME is a major cause of hearing impairment and this effect is a matter of serious concern, particularly in children, because it may have long term effects on early communication, language development, auditory processing, psychological and cognitive development and educational progress and achievement.

On the basis of the findings of the study certain recommendations are general health promotion 
measures; breast feeding and hygiene are systematically encouraged and strengthened in communities concerned. Avoidance of smoking, improved housing, reduced over crowding and adequate access to clean water should be considered wherever possible. Primary ear care should be incorporated into primary health care (PHC). The diagnosis of OME needs to be made earlier to prevent its long term effects especially on hearing impairment. Health educations to aware people, Feasibility should be ensured.

\section{References:}

1. Castagro LA (1987) Otitis media with effusion in children. Annals of Otorhinolaryngology, 78. suppl. 68:5-6.

2. Williamson IG, Duleavey J, Bain J, Robinson D, The natural history of otitis media with effusion a three-year study of the incidence and prevalence of abnormal tympanograms in four South West Hampshire infant and first schools, J Laryngol Otol 1994 Nov; 108(11):930-4.

3. Minia BM, Machemba A, Prevalence of otitis media, jearomg impairment and cerumen impaction among school children in rural and urban Dar es Salaam, Tanzania, Int J Pediatr Otorhinolaryngol 1996 sep; 37(1):29-34.

4. Kim CS, Jung HW, Yoo KY, Prevalence of otitis media and allied diseases in Korea-results of a nation-wide survey, 1991, J Korean Med Sci 1993 Feb;8(1):34-40.
5. Saim A, Saim L, saim S, Ruszymah BH, Sani A, Prevalence of otitis media with effusion amongst pre-school children in Malaysia, Int J Pediatr Otorhinolaryngol 1997 Jul 18;41(1):21-8.

6. Rassmussen F. (1993) Protracted secretory otitis media. The impact of familial factors and daycare center attendance. International Journal of Pediatric Otorhinolaryngology. 36.29-37.

7. Strachan D.P, Jarvis M J and Feyerabend C. (1989) Passsive smoking salivary concentrations and middle ear effusions in seven year old children. British Medical Journal, 298, 1549-1552.

8. Hinton A. E. (1989) Surgery for otitis media with effusion in children and its relationship to parental smoking. Journal of Laryngology and Otology. 103, 559-561.

9. Maw A. Glue ear in childhood. Clinics in Developmental Medicine 135. MacKeith Press, 1995.

10. Teele D. Klein I, and Rosner B. (1980) Epidemiology of otitis media in children. Annals of Otorhinolaryngology, 89. suppl. 68,5-6.

11. Morimoto K, Narita S, Kawaguchi E, Yamagishi M, Kataura A., Epidemiological analysis of otitis media with effusion in children, Nippon Jibiinkoka gakkai Kaiho 1991 May; 94(5):678-84.

12. Miller SA, Omene JA, Bluestone CD, Torkelson DW, A point prevalence of otitis media in a Nigerian village, Int J Pediatr Otorhinolaryngol 1983 Jan; 5(1):19-29. 